This item was submitted to Loughborough's Research Repository by the author.

Items in Figshare are protected by copyright, with all rights reserved, unless otherwise indicated.

\title{
How women engineers do and undo gender: consequences for gender equality
}

PLEASE CITE THE PUBLISHED VERSION

http://dx.doi.org/10.1111/j.1468-0432.2008.00406.x

PUBLISHER

(C) 2008 The Author(s); Journal compilation @ 2008 Blackwell Publishing Ltd

VERSION

AM (Accepted Manuscript)

LICENCE

CC BY-NC-ND 4.0

\section{REPOSITORY RECORD}

Powell, Abigail, Barbara Bagilhole, and Andrew R.J. Dainty. 2019. "How Women Engineers Do and Undo Gender: Consequences for Gender Equality”. figshare. https://hdl.handle.net/2134/11113. 
This item was submitted to Loughborough's Institutional Repository (https://dspace.lboro.ac.uk/) by the author and is made available under the following Creative Commons Licence conditions.

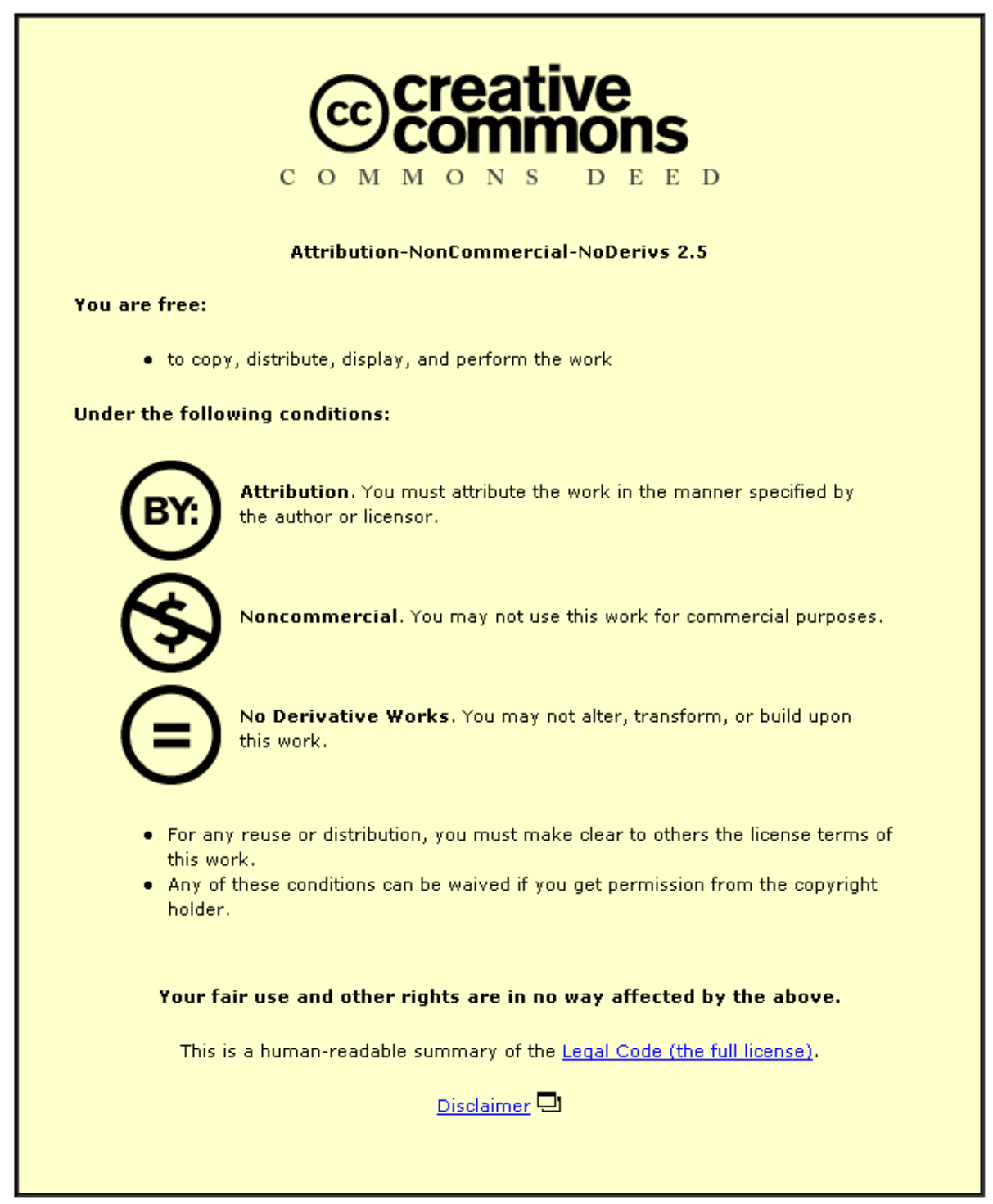

For the full text of this licence, please go to: http://creativecommons.org/licenses/by-nc-nd/2.5/ 
Gender, Work and Organization.

\section{How Women Engineers 'Do' and 'Un-do' Gender: Consequences for Gender Equality}

Abigail Powell, ${ }^{*}$ Barbara Bagilhole and Andrew Dainty

\section{Abstract}

The image of engineering as a masculine profession has reproduced the perception that engineering is unsuitable for women. While various strategies have attempted to increase the number of women entering engineering education and employment, their success has been limited. At the same time, it has been argued that the way gender is 'done' in work can help diminish or increase inequality between the sexes. Using empirical research exploring women engineering students' workplace experiences, this paper considers how gender performance explains the behaviour and attitudes of women engineering students. Butler (2004) implied that doing gender can result in our being undone. This was specifically found to be the case for the women students in this study, who performed their gender in a particular way in order to gain male acceptance. In doing this they utilized certain coping strategies: acting like one of the boys; accepting gender discrimination; achieving a reputation; advantages over disadvantages; and adopting an 'anti-woman' approach. These strategies are part of women's enculturation and professionalisation into engineering, yet they also fail to value femaleness; in 'doing' engineering, women often 'undo' their gender. Such gender performance does nothing to challenge the gendered culture of engineering, and in many ways contributes to maintaining an environment which is hostile to women.

Keywords: gender, culture, engineering, women, organisation

\section{Introduction}

West and Zimmerman (1987) suggest that men and women 'do' gender in social interaction, despite perceiving that they act in gender free or gender neutral ways. Since people bring their beliefs about gender into social relations with little thought, gendered performance is pervasive and taken for granted (Ridgeway, 1997). While participants in organisational culture may believe they express personal taste and

\footnotetext{
"Address for Correspondence: Abigail Powell, Department of Civil and Building Engineering, Loughborough University, Loughborough, LE11 3TU, e-mail: A.Powell@Lboro.ac.uk
} 
inclinations, Gherardi (1994) maintains that knowledge of what fits with the organisational style is an acquired skill. Gherardi therefore argues that the way we 'do' gender in work can help diminish or increase inequality between the sexes. Added to this, Butler (2004) has implied that doing gender can result in our being undone. For example, women may perform their gender in a particular way in order to gain male acceptance, but this, in turn, may implicitly devalue femaleness. In other words, the terms on which we are accepted as fitting into an organisation, may make our life unliveable, yet the option of not fitting in or being recognised may also lead to a life not worth living (as Pullen and Knights (2007) following Butler contend).

This paper reports on empirical research exploring women engineering students' workplace experiences. The paper deconstructs women's experiences using theoretical arguments to investigate how gender gets done and undone in everyday organisational practice. Specifically, the paper considers theories surrounding the construction and performance of gender and the gendering of organisations, before demonstrating how the concept of gender performance can be used to explain the behaviour and attitudes of women engineering students in a male dominated environment.

\section{Women in Male Dominated Environments}

Etzkowtiz et al. (2000) found that women face a series of gender related barriers to success in male-dominated careers. Women are typically viewed as 'honorary men' or 'flawed women' for attempting to participate in fields traditionally dominated by men. Similarly, Evetts (1997) writes that if the woman is an efficient, competent manager, she is likely to be judged unfeminine, but if she demonstrates the supposedly female qualities of care and sensitivity she is likely to be assessed either as an inappropriate and inefficient manager, or as a good female manager. Numerous research studies indicate that women who seek entry into male-dominated cultures either have to act like men in order to be successful, leave if they are not adaptable to the culture, or remain in the industry without behaving like men but maintaining unimportant positions (see Bennett et al., 1999).

In an early study Kanter (1977) showed how non-traditionally employed women were forced to permit 'majority cultural expressions' in their presence. Such loyalty to the dominant group can also be demonstrated through women allowing themselves to provide a source of humour for the group, often colluding with dominants in doing so. 
However, 'fitting in' reinforces, rather than challenges, the dominance of the majority group. Whittock (2002) proposes two ways in which tokens can respond to 'boundary heightening': women can accept isolation, which risks exclusion from informal socialisation; or, women can attempt to become an insider (or 'one of the boys'). Assimilation is described by Kanter as the way in which dominants distort the characteristics and behaviour of tokens to fit their stereotyped images of how token women should behave. Token women can object to this, or accept some form of 'role entrapment' by adopting restricted and often caricatured roles within the system, e.g. 'the mother', who is empathetic, a characteristic to be utilised 'on the job'. Cohen and Tyler (2007) term this a process of 'purification', rendering some women acceptable, whereby women are constructed as an organisational resource, available and accessible to all.

Dryburgh (1999) argues that assimilation is actually a process of professionalisation by engineering students (women and men), which requires adaptation to the professional culture, internalisation of the professional identity and solidarity with others in the profession (see also Faulkner, 2006). For women, the success of cultural adaptation, may also include the management of their own gender. Dryburgh maintains this is likely to include defining sexist behaviour as exceptional, working hard to show solidarity with male colleagues and accepting uncritically the masculine culture into which they are entering. This is also linked to Goffman's (1959) concept of 'impression management', whereby a range of actions are used to project an impression of self that the individual hopes will elicit a desired response or reaction in others. Similarly, those who do not conform to the cultural values and norms of the engineering profession, will be weeded out from an early stage (Dryburgh, 1999).

Gherardi (1994) suggests that when women are actually accepted into a traditionally masculine environment, they are often made the object of displays that typify the community of men. A remark made to Gherardi on several occasions in her investigation concerned the symbolic 'slap on the back.' This situation is illustrated by Gherardi's story of a woman engineer in an all male research team. After rejecting the advances of her colleagues, the woman was marginalised and teased as an 'angry feminist'. This situation changed dramatically when her boss publicly praised her work and as a sign of appreciation, gave her a hearty slap on the back. Often when a woman gains acceptance by men, and when her work is valued, forms of communication normally exclusive to men are extended to include her as well. The implicit devaluation of femaleness is either unobserved or taken for granted. 
Gherardi (1994) questions how women react to the symbolic 'slap on the back'. How do women react to situations where they are accepted as people but devalued as women? If they respond to only one of the terms of the message, they ignore and disqualify the other. They resort to a collusive manoeuvre to become honorary men, thus disqualifying their gender, or else they save the honour of their gender but show poor communication skills by ignoring the main content of the message thereby gaining acceptance.

In addition, gender, as distinct from sex, can be articulated by Simone de Beauvoir (1949) who concluded that it is not biological, psychological or economic factors that shape the prescribed difference between men and women, but rather, 'woman' is socially constructed as the other. Furthermore, Borgerson and Rehn (2004) indicate that the dualism of masculinity and femininity means that men and women have been positioned as opposites, with "naturally opposing gender traits, prescribing roles and rules" (2004: 459). Gherardi (1994) suggests that in this binary positioning, the interdependence of terms is hierarchical with maleness/masculinity being treated as superior and the femaleness/femininity being derivates. We are therefore trapped by a process of binary opposition, whereby what we affirm with one term, we negate with the other. Butler (1990) has maintained that the ramifications of Beauvoir's deconstruction of gender are more far-reaching. Not only does the separation of sex and gender loosen the restrictions on social roles, but also insinuates that there are different sorts of being. This implies that a certain sex does not necessitate a certain gender, although there are powerful cultural constraints (Cole, 2000). Thus, those beings categorised as female need not aspire to, or need not be the only one to aspire to, 'womanhood'. According to West and Zimmerman (1997: 126) gender "is the activity of managing situated conduct in the light of normative conceptions of attitudes and activities appropriated for one's sex category." In other words, gender is something we think, something we do and something that we make accountable to others: "Doing gender involves a complex of socially guided perceptual, interactional and micropolitical activities that cast particular pursuits as expressions of masculine and feminine natures" (ibid.).

Gherardi's (1994) early research findings exemplify Butler's (2004) notion of what it might mean to undo restrictively normative conceptions of gendered life. While a normative conception of gender can undo one's personhood, undermining the capacity to persevere in a liveable life, the experience of becoming undone can also undo a prior conception of who one is only to inaugurate a relatively newer one that 
has greater liveability. Thus, while women are becoming undone in a good way, and breaking barriers about womanhood, by entering male dominated arenas, they are simultaneously becoming undone in a bad way, as a result of disqualifying their gender in order to be successful in that arena. Similarly, Meyerson and Scully (1995) have suggested that some individuals do not easily fit within the dominant cultures of their organisations or professions. These individuals, in this case women in engineering, must continuously manage the tension between personal and professional identities that are at odds with one another. Some individuals cope with this by leaving mainstream employment, while others may, consciously or subconsciously, silence their complaints and surrender their (female) identity.

Gherardi (1994) maintains that doing gender is essentially getting to grips with an ambiguity that, scientifically, we lack the instruments to cope with. Our experiences of managing and building gender are characterised by contradictions and doublebind situations (for example, where women who are considered feminine will be judged incompetent, and women who are competent unfeminine), by ambivalence and uncertainty because these are the constitutive elements of the opposition between male and female and their intimate indivisibility.

\section{Women in Engineering}

The research presented in this paper is based on a longitudinal research project investigating the influence of women engineers' earliest encounters with engineering workplaces on their future career intentions. The study explores the experiences of women students from a range of engineering disciplines, including construction/civil, aeronautical, mechanical, design and technology.

Nancy Lane, co-author of 'The Rising Tide' report on women in science, engineering and technology, has commented that, "Engineering ... is a subject where women are currently catastrophically underrepresented" (1997: 41). That women remain a minority in engineering has been explained in various ways, including poor or inadequate guidance counselling prior to entering university; early differential socialisation of men and women; lack of support from family, friends and professional engineers; and cultural and occupational barriers (Dryburgh, 1999). Sagebiel (2003), for example argues that various studies have shown that what drives women away from technology are not women's deficits in abstract thinking, but the content and 
climate prevalent in academia, which construct an atmosphere of dominant masculinity.

A business case (rather than a desire for more inclusive organizational cultures) has been argued for the increase of women in the engineering sector. Bagilhole (1997) suggests this essentially rests on two premises: that the population's full range of skills and talents is neglected as a result of the exclusion of women and other minorities; and that by projecting a more pluralistic self-image, business can widen the pool of potential customers. This argument has resulted in several UK government initiatives aimed at encouraging women to pursue engineering careers. These initiatives have had some success in increasing the proportion of women studying engineering. Glover (2000) for example, showed that in 1973 only 3\% of engineering and technology graduates were women, compared to $15.8 \%$ in 2005/06 (HESA, 2007), although figures vary widely by discipline. This, however, is still significantly below the average across all subjects (57\%) (HESA, 2007). In fact, only $1.6 \%$ of all women students in higher education are based in engineering (HESA, 2007), suggesting that while the number of women studying engineering has increased, this is, in part, attributable to the rise in women students across all university disciplines. Furthermore, the increase in women engineering students has failed to translate into an equivalent increase in women engineering professionals; in 2006 women only accounted for $5.4 \%$ of engineering professionals aged 16-65 (ONS, 2007).

The central role of engineering in society and the economy is not evident to the public at large or to the media in particular. The engineering profession is, according to Malpas (2000), considered by many as a somewhat dull, uncreative activity, associated with the so-called 'old-economy'. Historically the image of engineering has been tough, heavy and dirty; culturally the image of engineering is a masculine profession. This is not only because the workforce is dominated by men, but also because the prevailing culture and ethos of the industry are extremely male (Evetts, 1998). These cultural images have helped to reproduce the perception that engineering is unsuitable for women. This is a somewhat circular process, reinforcing the masculinity of the industry. It has been argued that this is a result of the polarised characteristics supposedly attached to gender in the process of socialisation. Sagebiel (2003) states that engineering can be considered gendered in three ways. First, gendered structures are visible in gender difference in the division of labour and in the work styles of women and men. Second, the symbols and 
images of engineering knowledge and practice are gendered through cultural associations between masculinity and technology. And third, individual engineers have gendered personal and professional identities and experiences.

Empirical evidence suggests that women suffer if they go against such cultural dictates (Evetts, 1998). This is supported by Glover et al. (1996) who indicated that women actively choose not to enter science, engineering and technology (SET) careers in the knowledge that they are likely to feel discomfort. Although women can cope with the actual engineering work, they are likely to find it much more difficult to cope with the engineering culture (Evetts, 1998) and the values, systems and performance criteria which have been set up by men, for men, and not for women (Opportunity 2000, 1996). Some women therefore pay both personal and social costs for working in a male dominated field (Bagilhole, 2002). By contrast, Bennett et al. (1999) claim that women who seek a career in SET industries are socialised into its culture through the education system and appear actively to seek that culture. Gale (1994) described gender values as a continuum ranging from masculine to feminine and suggests that women holding similar values are attracted to similar occupations. Nevertheless, many women reject the masculine engineering culture, as do many men (Bennett et al., 1999).

\section{Research Design}

The research adopted a qualitative approach to explore the experiences and reflections of women engineering students. Purposive sampling was undertaken of second year women engineering undergraduates since students must decide in this year whether or not to undertake the industrial placement. The industrial placement was specifically targeted as this is usually women's first major contact with the engineering sector, and a key transitional stage in each students' process of becoming a professional engineer (or not). Access to the students was facilitated through university databases, programme coordinators and industrial placement coordinators in engineering, and related, departments. From this point, the interviewees were self-selecting, and while this may have resulted in a sample that is not representative of women engineering students generally, the range and number of interviews is broad enough to be indicative of women students' experiences.

Two semi-structured interviews were conducted with a total of 26 industrial placement students. The first interviews took place while women were in their 
second year of study, with the second interviews took place the following year when the students were on their industrial placements. Two focus groups of the same women were then conducted following the students return to university for their third year of study. The focus groups were designed to explore how women's attitudes and career intentions had changed as a result of their placement experiences, and to allow the women to compare and contrast their experiences. The pre-placement interview stage of the research was complemented with an additional 26 interviews with women second-year undergraduates who chose not to go on industrial placement.

The use of a semi-structured interview guide for the interviews meant that key issues identified by the researchers could be explored, whilst at the same time interviewees could define issues according to their own experiences and understandings. Within the context of the wider research project, the interviews explored a range of issues, including, for example, influences and reasons for studying their chosen degree, experiences of their learning environment, reasons for choosing/not choosing to go on placement, the transition to work, placement experiences and, future career intentions.

The interviews, with the agreement of the women, were tape-recorded and the focus groups video-recorded. All the data were then transcribed verbatim and anonymised, before being analysed with the computer software NVivo. NVivo was used to employ an approach informed by Grounded Theory, searching for meaning in the data and generating theory from rich, detailed descriptions in the interview transcripts. The initial analysis began with open coding, breaking down, examining, comparing, conceptualising and categorising the data (Strauss and Corbin, 1990); axial coding then ensured relationships between categories were systematically developed and that all similarities and differences were captured in the final analysis (Langdridge, 2004). The cumulative analysis of the findings led to the eventual development of theories and explanations grounded in the data, reflecting the complex nature of the social phenomena investigated.

\section{Gender Performance}

The research revealed how women do and undo their gender in engineering organizations. As Paechter (2001: 49) argues, gender is not a given, it is a performance, and "we demonstrate our gender identity, by and large, by the playing 
out of gender roles, and these roles are learned - usually unconsciously". The performance of gender was particularly evident through the strategies women were found to adopt for coping in a male dominated environment:

\section{Acting like one of the boys}

Women were found to actively perform masculinity, attempting to fit in with their male colleagues by showing that they did not require special treatment and by sharing their camaraderie:

I give them as good as I get. So it's equal. And you have a laugh. If you give them respect, they'll give you respect back (Suzanne, Engineering Environmental Technology student).

This is similar to what Sheppard (1989: 146) described as a strategy of "blending in and claiming a rightful place". Sheppard found that 'blending' depended on the management of being both feminine enough, in terms of appearance, selfpresentation and acceptance of expectations, and business-like enough, in order to claim a place in the organisation. Moreover, Knights and Kerfoot (2004), for example, found that 'career-women' demonstrate "that masculinity is not the exclusive preserve of men. [Women] apparently see no alternative other than to emulate men in order not to be compared negatively with them or to suffer from the stereotypes that masculine hegemonic organisations reproduce" (2004: 447). Schmitt et al. (2003) also argue that conforming to organisational norms and displaying masculine behaviour may be necessary to avoid stereotypical performance expectations based on one's sex. However, this strategy can also backfire, as women who conform to masculine work roles may be penalised for not being 'womanly enough.'

\section{Accepting gender discrimination}

Similar to Dryburgh's (1999) findings that obvious examples of sexism are labelled by women as exceptions, the women in this study were reluctant to admit they had been discriminated against, frequently seeking ways to justify their colleagues' actions. For example, they may suggest that their colleagues did not have the intention to discriminate against them, or that the consequences of their colleagues' action was ultimately good for them despite their intentions:.

You get the obvious, you know, bits of perving and stuff like that, but you've just got to learn to take it in the spirit that it's meant (Hannah, Civil Engineering student). 
I've just been pushed out ... but being thrown in at the deep end is quite a good way to learn this job (Carolyn, Transport Management student).

Carolyn also went on to suggest that she did not always deserve to be treated equally:

There's a guy working there with me, he started a month before me ... I just found out he got a bonus in his pay packer for helping round the office in the first few weeks before I was there. To be honest, I don't think I'll get that, you know, he is an exceptionally good student (Carolyn, Transport Management student).

One student also described discovering her colleagues had taken a bet as to how long she would last on the placement. Rather than being annoyed or upset, the student interpreted the situation as a compliment, as her colleagues were impressed that she had lasted so long! This reminds us of Kanter's (1977) idea of 'role entrapment' and a response to what Whittock (2002) calls 'boundary heightening', whereby challenging discriminatory behaviour is rejected due to the risk of exclusion or isolation. As Schmitt et al. (2003) explain, women will tend to avoid perceptions of social reality that have negative implications for their social identity unless evidence for those perceptions is unambiguous. In other words, perceiving one's performance as the cause of a negative outcome is less damaging to an individual than perceiving discrimination as the cause. Furthermore, Walker (2001) has also suggested that, as a result of normalisation, rather than gender equity, women engineering students are either ambivalent towards, or reject, gendered explanations of their experiences.

\section{Achieving a reputation}

Women sought to overcome any perceived discrimination or negative attitudes by demonstrating that they were good, capable engineers, and believed that consequently their gender would be insignificant:

Once l'd proved that I was there to just get on with it, I think that kind of barrier just went (Chloe, Mechanical Engineering student).

In a comparable study, the women in Evetts's (1998) study argued that it was necessary to be a good engineer. Focusing on building a reputation and earning respect, women engineers perceive that they will be seen as engineers first, women second, rather than women first as is often the case. However, Evetts argues that 
problems and difficulties remain, particularly in relation to career and promotion in the organisation. To build a reputation and to become a good engineer can be extremely difficult when there is much competition surrounding career development and promotion, where there are numerous highly motivated, achievement-oriented individuals competing for every promoted post. Despite descriptions of attitudes and experiences to the contrary, Walker (2001), similarly, found that women engineers perceive that the only thing that matters is their ability to do the job well (and not their gender).

\section{Advantages over disadvantages}

Women suggested that the advantages of working in engineering outweighed the disadvantages of being a woman in a male dominated environment. Although they recognised that there were negative aspects about engineering, for them as women, they felt that positive aspects balanced them out at present:

I might have had disadvantages that I didn't realise but I guess the advantages outweigh them (Alison, Mechanical Engineering student).

In the construction industry, sometimes they would look at you like, 'oh, you don't understand this and that', but when you get to do something very well, they praise you ... We are at a disadvantage but also an advantage in a way (Anna, Quantity Surveying student).

The idea of advantages outweighing disadvantages is particularly important, as it implies a potential for the balance to be tipped in the opposite direction. It may also go some way to explain why, in this study, the picture of women at the outset of their careers appears, on the whole, more positive than that of women engineers more established in their careers (e.g. Bagilhole, 2000; Evetts, 1998).

\section{Adopting an 'anti-woman' approach}

The women provided evidence of passively performing masculine gender by conforming to dominant, hegemonic masculinity and by rejecting femininity. Women engineering students were found to value their status as 'a novelty' in engineering. Sinclair (2005) suggests that the 'Queen Bee' syndrome - a reluctance to associate with other women, and appearing more 'macho' than some men - may simply be a result of being more comfortable with men than women. In the case of women engineers, these women have often become accustomed to a male dominated environment through technical hobbies, and the choices they have made in 
education. Whatever the origins of male-identification, Sinclair goes on to say that "these women enjoy the company of men, share interests and aspirations that are typically characterised as masculine, and perhaps seek their approval" (2005: 139). Women in the study presented here were also critical of women engineers who were perceived as using 'feminine tactics' (such as crying) and, perhaps most strikingly, held traditionally stereotypical views of women outside engineering.

I wanted to do [engineering] because not that many girls are doing it and, to be honest, sometimes I think that girls are irritating (Michelle, Civil engineering student).

These attitudes may be a result of women's assimilation or professionalisation into the engineering culture (cf. Dryburgh, 1999; Faulkner, 2006). Maupin and Lehman (1994) also found that, in a study of accounting organisations, it was necessary to suppress or eliminate attitudes and behaviours that would identify individuals as 'typically female'. Adopting an 'anti-woman' approach is a further way of disidentifying with one's own gender, and arguably a strategy adopted in order to succeed in the workplace (see also, Goffman's (1959) 'impression management'). However, such attitudes fail to question let alone challenge the status quo. Any career success among such women is unlikely to promote the interests of women in the sector generally (Greed, 2000). It also raises questions about the concept of a 'critical mass': the idea that once there is a sufficient proportion of women in engineering, the traditionally masculine culture will no longer prevail (see Powell et al. (2006) for further discussion of critical mass). As Sinclair (2005) highlights, by the time women achieve positions of formal power they have learned and share similar influencing strategies to their male colleagues: "they have become enculturated" (2005: 110).

Similarly to the women in Evetts's (1998) research, the management of gender was seen to lie in women's own hands, and was perceived as being related to personality. However, these individualistic coping strategies can be viewed as just that - 'coping mechanisms', rather than solutions to the problems women face. Such strategies therefore fail to challenge the existing cultures and structures in engineering, which may be the only genuine (if difficult to achieve) way of improving women's experience and role in engineering.

\section{Gender Conflict}


Gender conflict is found when women were performing feminine gender. Women engineering students overwhelmingly stated they were more likely to ask for help both in the engineering classroom and in the workplace. Also, their sex was, unwittingly, likely to ensure that they received more help and co-operation than their male counterparts:

One lecturer does give us a lot more leeway than he'd give the lads (Isabella, Mechanical Engineering student).

I think some of the male lecturers are more helpful to the girls than to the guys (Elizabeth, Design and Technology student).

While a number of women found this attitude patronising, most perceived it as positive, with some indications that women purposely use their gender in order to get more help. However, this finding may indicate that women in engineering are seen as less capable than their male counterparts; ultimately a fact which, in the future, may cost women in terms of promotion.

The findings also reveal gender as a site of conflict when women seek to establish themselves in an arena traditionally conceived of as masculine. For example, the women in the research perceived themselves to be more employable as a result of their sex. It was felt that companies were trying to recruit more women in order to improve their image. Whilst a drive to recruit more women into the industry is a positive step, this had the effect of making women doubt their own abilities ('Have I been employed for my capabilities or my gender?'). Alternatively, this also led women to believe, possibly falsely, that engineering workplaces would be equitable to women, posing the question of whether 'getting in' is the same as 'getting on' in engineering industries:

I felt like they only employed me because I was a girl and yet they didn't want me to act feminine (Debra, Quantity Surveying student).

One guy ... said you are bound to get [a bursary] because at the end of the day they really need girls in engineering. And it really, really upset me Sophie, Mechanical Engineering student).

These findings all suggest that women engineering students experience gender role conflict, performing gender as is deemed appropriate in any given situation. This supports Faulkner's (2006) argument that challenging offensive behaviour risks 
alienation from colleagues. Within the structure of engineering organisations, the majority of women did not consider it feasible to challenge gender discrimination:

I don't think I would have much to achieve if I was to pursue sexual discrimination. I think it would highlight the case that women can be a bit of a pain in the arse (Carolyn, Transport Management student).

Instead, women used their agency to act within these social constraints by consciously and subconsciously adopting the coping strategies described above.In addition, whilst there are multiple masculinities and femininities that can be performed by anyone, only 'traditional' masculinity performed by men is valued in engineering cultures specifically and by society generally. This means that women in engineering face further role conflict because they are perceived as defective women for choosing the 'masculine' occupation of engineering, and also as defective engineers because they are not men. In other words, while some women engineers may deny or reject femininity in order to gain acknowledgement, only male masculinity is likely be accepted because this appears to be the norm (Halberstam, 1998). This reinforces the argument for moving beyond a bipolar distinction between masculinity and femininity, the interdependence of which is hierarchical (Derrida (1967) quoted in Gherardi (1994)) treating 'male' as superior and 'female' as a derivate or 'other'.

Butler (2004: 2) suggested that "certain humans are recognised as less than human, and that form of qualified recognition does not lead to a viable life. Certain humans are not recognised as human at all, and that leads to yet another order of unlivable life". Applying this to engineering women are caught in an ambiguous, double-bind where they can choose to be accepted, for example by acting like 'one of the lads', but simultaneously deny their gender, or choose not to be accepted all. Bagilhole et al. (2006) found that women engineers often chose to flee their gender declaring themselves 'engineers' not 'women engineers' who fail to realise that it is primarily appearance that is socially exclusionary (Garland-Thomson, 2005). Miller (2002: 154), for example, found that despite women's occupational and organizational values, beliefs and behaviour being consistent with traditionally masculine norms, they still described feeling like 'outsiders', as they were criticised if their behaviour 'slipped' to reflect more feminine values. Miller suggests this is testament to the absoluteness of the general belief in a binary gender system. Miller goes on to argue, that while gender is socially constructed and separate from sex, this has little effect in reality. While women engineers destablise gender roles by acting like men, 
the salience of the perception that they are still women takes precedence (Miller, 2002). It is therefore important to develop a positive gender identity for women engineers.

Some conflict may also occur because of the implication that women now compete on equal terms with men (Wajcman, 1998). Certainly the formal implementation of equality policies is widespread, and as a result, there is much less overt sex discrimination. However, rather than dying out, male power is being reconstituted in a new form and the new gender regimes are oppressive to women in their own way (Wajcman, 1998, p.30). MIT (1999), for example, found that women science academics began their careers with the perception that gender discrimination had been solved, but later realized this was not the case. Rather "their eyes were opened to the realization that the playing field is not level after all and that they had paid a high price both personally and professionally as a result" (MIT, 1999: 9). In order to succeed, women are compelled to deny aspects of themselves and to become more like men. However, systematic inequalities between men and women ensure that their experiences cannot be the same. Women are constituted as different kinds of workers because of their relation to the domestic sphere and because their bodies are sexualized to a degree that men's bodies are not.

\section{Conclusions: Multiple femininities and masculinities}

As Gherardi (1994) pointed out, the multiple contradictions and ambiguities make 'doing gender' difficult to deconstruct. In order to make sense of the findings presented in this paper, it is useful to perceive of multiple masculinities and femininities in the doing of gender. While this idea of gender multiplicity has been critiqued for leaving the gender divide in place (Linstead and Brewis, 2004), its use here is not intended to reproduce the hierarchical divide between masculinity and femininity, but rather, to provide a framework that allows researchers to explore the 'doing' and 'undoing' of gender. In this sense, the construction of 'men' does not accrue exclusively to the bodies of males or mean that 'women' will interpret only into female bodies (Butler, 1990). Thus a certain sex does not necessitate a certain gender, although there are powerful social constraints (Cole, 2000). Individual women combine traditional perceptions of both masculinity and femininity. Thus, as demonstrated in the research findings, women engineers are neither 'typically' feminine nor 'typically' masculine. 
It is also important to note that different masculinities and femininities will be adopted and performed, both actively and subconsciously, at different times by individuals. Sinclair (2005) argues that women may well prove to be bi-gendered in their approach. That is, they learn an array of influence tactics depending on the context, who they are working with, how much power they have and whether influencing upwards or downwards. This goes someway to explain the apparently contradictory attitudes of women engineers in this research. For example, at one given time it may be necessary for women engineers to 'achieve a reputation' as a competent engineer, but at other times women will accept offers of help from their male colleagues. While these are very different strategies, they both have the same aim: to gain acceptance. Thus the women engineering students were found to perform their gender in a number of ways as part of their assimilation and professionalisation into the engineering industries, but also for themselves, because "we create and reinforce our gender identity by the performance we put on" (Paecheter, 2001: 50). However, both gender performance and gender conflict depict women as organizationally abject; 'overexposed' on the one hand, and yet 'isolated' on the other, which Cohen and Tyler (2007: 11) suggest is a result of living a "negotiated, negated identity".

This approach seeks to destabilise the existing binary divide between men and women, and also calls for new ways to tackle inequality, as it supports the idea for an alternative initiative that is neither based on the sameness or difference between men and women. The findings indicate women's assimilation into the masculine engineering cultures through processes of gender performance. Furthermore, because of women's adaptation to masculine cultures, including the denial of sexism, the obstacles women in engineering face are likely to remain (Dryburgh, 1999). Combined with the relatively slow progress made by equal opportunities perspectives on the issue of women in engineering and calls to problematise gender as binary, there is, as Phipps (2006) has argued, a need to develop a more critical and radical feminist consciousness.

This paper has explored how gender is performed by women engineering students, in order to gain male acceptance. In doing this we have showed how they utilize the following coping strategies: acting like one of the boys; accepting gender discrimination; achieving a reputation; advantages over disadvantages; and adopting an anti-woman approach. Gender is also raised as a site of conflict for women engineers, often faced with the challenge of managing tensions between personal 
and professional identities which are often at odds with one another. Such tensions arise particularly from the double bind effect, whereby women engineers who perform in highly feminine ways are likely to be considered incompetent and competent women engineers are seen as unfeminine; thereby instilling a norm whereby only male masculinity is likely to be accepted in the current situation. Future research in this area may address if and how women engineers' 'doing' or 'undoing' of gender changes with the effect of cumulative experience; i.e. do women engineers' performance of gender change as they progress through their careers? Given this paper's focus on women's gender performance, it is also necessary to explore how men construct themselves in engineering organisations, since masculine hegemony may also be repressive for at least some men (Knights and Kerfoot, 2004), and with particular consideration of multiple masculinities. In conclusion, this paper supports Sagebiel's argument that engineering is gendered and, demonstrates some of the practical utility of Butler's ideas surrounding 'undoing gender'. It shows how women's enculturation or professionalisation into engineering results in their doing gender in a particular way in order to be accepted as fitting into the life they have chosen as engineers. However, this simultaneously results in women's implicit and explicit devaluing and rejection of femaleness; in 'doing' engineering, women have 'undone' their gender, failing to challenge the gendered culture of engineering, and in many ways upholding an environment which is hostile to women.

\section{Acknowledgements}

This research was supported with a grant from the Economic and Social Research Council (RES000230426). We are grateful to the universities and particularly the students who took part in the interviews that form the basis of the findings presented in this paper.

\section{References}

Bagilhole, B., Dainty, A. and Neale, R. (2006) Women Engineering Students' Workplace Experiences: Impact on Career Intentions. ESRC Report (RES000230426).

Bagilhole, B. (2002) Women in Non-Traditional Occupations: Challenging men. Basingstoke: Palgrave Macmillan.

Bagilhole, B. (1997) Equal Opportunities and Social Policy: Issues of gender, race and disability. London: Longman. 
Beauvoir, S. (1949) The Second Sex. Translated and edited by H.M. Parshley (1993) London: David Campbell Publishers.

Bennett, J.F., Davidson, M.J. and Gale, A.W. (1999) Women in Construction: A comparative investigation into the expectations and experiences of female and male construction undergraduates and employees, Women in Management Review, 14 (7), pp.273-91.

Borgerson, J. and Rehn, A. (2004) General Economy and Productive Dualisms. Gender, Work and Organization, 11 (4): 455-474.

Butler, J. (2004) Undoing Gender. London: Routledge.

Butler, J. (1990) Gender Trouble. London: Routledge.

Cohen, L. and Tyler, M. (2007) The In/Visible Woman: Gender, Abjection and Organisation. Unpublished paper presented to Women and Gender Studies Research Group, Loughborough University, March 2007.

Cole, L. (2000) (Ed.) Encyclopedia of Feminist Theories. London: Routledge. Dryburgh, H. (1999) Work Hard, Play Hard: Women and professionalisation in engineering - adapting to the culture, Gender and Society, 13 (5): 664-682.

Etzkowitz, H., Kemelgor, C. and Uzi, B. (2000) Athena Unbound: The advancement of women in science and technology. Cambridge: Cambridge University Press.

Evetts, J. (1998) Managing the technology but not the organization: women and career in engineering. Women in Management Review, 13 (8): 283-290.

Evetts, J. (1997) Women and Careers in Engineering: Management changes in the work organisation. Women in Management Review, 12 (6): 228-233.

Faulkner, W. (2006) Genders In/Of Engineering: A research report. Edinburgh: University of Edinburgh. Available at:

http://extra.shu.ac.uk/nrc/section 2/publications/reports/Faulkner Genders in Engin eering Report.pdf [Accessed January 2007].

Gale, A.W. (1994) Women in Non-traditional Occupations: The construction industry. Women in Management Review, 9 (2): 3-14.

Garland-Thomson, R. (2005) Feminist Disability Studies, Signs: Journal of Women in Culture and Society, 30 (2): 1557-1587.

Gherardi, S. (1994) The Gender We Think, The Gender We Do in Our Everyday Lives, Human Relations, 47 (6): 591-610. 
Glover, J. (2000) Women and Scientific Employment. Basingstoke: Macmillan. Glover, J., Fielding, J. and Smeaton, D. (1996) What Happens to Women and Men with SET Degrees? Labour Market Trends, 104 (2): 63-67.

Goffman, E. (1959) The Presentation of Self in Everyday Life. Garden City, NY: Doubleday-Anchor.

Greed, C. (2000) Women in the Construction Professions: Achieving critical mass. Gender, Work and Organisation, 7 (3): 181-195.

Halberstam, J. (1998) Female Masculinitiy. London: Duke University Press. Higher Education Statistics Agency (2007) All HE students by subject of study, domicile and gender 2005/06. Available at: http://www.hesa.ac.uk [Accessed 10.05.06].

Kanter, R.M. (1977) Men and Women of the Corporation. New York: Basic Books.

Knights, D. and Kerfoot, D. (2004) Between Representations and Subjectivity: Gender binaries and the politics of organizational transformation. Gender, Work and Organization, 11 (4): 430-454.

Lane, N. (1997) Women in Science, Engineering and Technology: The Rising Tide Report and beyond. In: M. Maynard (Ed.) Science and the Construction of Women. London: UCL Press.

Langdridge, D. (2004) Introduction to Research Methods and Data Analysis in Psychology. Harlow: Prentice Hall.

Linstead, A. and Brewis, J. (2004) Editorial: Beyond Boundaries: Towards fluidity in theorising and practice. Gender, Work and Organization, 11 (4): 355-362.

Malpas, R. (2000) The Universe of Engineering: A UK perspective. Available at: http://www.engc.org.uk/publications/pdf/Malpas report.pdf [Accessed 29.04.04]. Maupin, R. and Lehman, C. (1994) Talking Heads: Stereotypes, status, sex-roles and satisfaction of female and male auditors, Accounting, Organizations and Society, 19 (4/5): 427-437.

Meyerson, D.E. and Scully, M.A. (1995) Tempered Radicalism and the Politics of Ambivalence and Change, Organization Science, 6 (5): 585-600.

Miller, G.E. (2002) The Frontier, Entrepreneurialism and Engineers: Women coping with a web of masculinities in an organisational culture. Culture and Organisation, 8 (2): 145-160. 
MIT (1999) A Study on the Status of Women Faculty in Science at MIT. MA.:

Massachusetts Institute of Technology. Available at:

http://web.mit.edu/fnl/women/women.pdf [Accessed November 2004].

Office for National Statistics (2007). Quarterly Labour Force Survey JanuaryDecember 2006. London: HMSO.

Opportunity 2000 (1996) Tapping the Talent. Available at: http://www.lboro.ac.uk/ orgs/opp2000/tapping.htm [Accessed 07.05.04].

Paechter, C. (2001) Using Poststructuralist Ideas in Gender Theory and Research. In: B. Francis and C. Skelton (Eds.) Investigating Gender: Contemporary perspectives in education. Buckingham: Open University Press.

Phipps, A. (2006) 'I can't do with whinging women!' Feminism and the habitus of 'women in science' activists, Women's Studies International Forum, 29: 125-135.

Powell, A., Bagilhole, B.M. and Dainty, A.R.J. (2006) The Problem of Women's Assimilation into UK Engineering Cultures: Can critical mass work? Equal Opportunities International, 25 (8): 688-699.

Pullen, A. and Knights, D. (2007) Undoing Gender: organising and disorganising performance, Gender, Work and Organization. 14(6): 505-511.

Ridgeway, C.L. (1997) Interaction and the conservation of gender inequality: Considering employment, American Sociological Review, 62: 218-235.

Sagebiel, F. (2003) New Initiatives in Science and Technology and Mathematics Education at the Formal Level: Masculinity cultures in engineering departments in institutions of higher education and perspectives for social change, GASAT 11 Conference: Gender, Science, Technology and Economic Paradigm Shift, 6-11th July 2003.

Schmitt, M.T., Ellemers, N. and Branscombe, N.R. (2003) Perceiving and Responding to Gender Discrimination in Organisations. In: S.A. Haslam, D. Van Knippenberg, M.J. Platow and N. Ellemers (Eds.) Social Identity at Work: Developing theory for organisational practice. Hove: Psychology Press.

Sheppard, D. (1989) Organisations, power and sexuality: The image and self-image of women managers. In J. Hearn, D. Sheppard, P. Tancred-Sheriff \& G. Burrell (Eds.) The Sexuality of Organisations London: Sage.

Sinclair, A. (2005) Doing Leadership Differently. Melbourne: Melbourne University Press. 
Strauss, A. and Corbin, J (1990) Basics of Qualitative Research. Newbury Park, CA: Sage.

Wajcman, J. (1998) Managing Like A Man: Women and men in corporate management. Cambridge: Polity Press.

Walker, M. (2001) Engineering Identities. British Journal of Sociology of Education, 22(1): 75-89.

West, C. and Zimmerman, D. (1987) Doing Gender, Gender and Society, 1 (2): 125151.

Whittock, M. (2002) Women's Experiences of Non-Traditional Employment: Is gender equality in this area possible? Constructing Management and Economics, 20: 44956. 